\title{
Research on the Innovation of Public Health Law Education under the Background of Free Trade Port Construction
}

\author{
Jiaqi Huang \\ Law School, Hainan Normal University, Haikou, China \\ 1154989376@qq.com
}

\begin{abstract}
In 2020, "Overall Scheme of Hainan Free Trade Port Construction" emphasized that Hainan should focus on developing modern service industry represented by medical and educational fields. In this context, the public health law education in Hainan, as a representative course integrating the dual characteristics of 'medical' and 'education', should also keep pace with the times to better meet the practical needs of the construction of Hainan free trade port. Through the extensive and in-depth investigation of five hospitals, two courts and five universities randomly selected in Hainan Province, and the analysis of 815 effective questionnaires collected by SPSS statistical method to form a survey database, the key and difficult points that need to be broken through in the innovation of Public Health Law education under the background of the construction of Hainan Free Trade Port are systematically summarized, and the scientific structure of strategic discipline orientation to improve the attention of Health Law, the adoption of immersion-type Health Law teaching methods.
\end{abstract}

Keywords: Free Trade Port Construction; Public Health Law Education; Innovation Research.

\section{Introduction}

As an important part of higher education in free trade port, public health legal education has become an indispensable research direction in the higher education system, especially under the influence of Covid-19. At present, few colleges and universities are carrying out public health law courses in Hainan, and colleges and universities have not formed a joint force in this field, resulting in uneven levels of legal education of public health students Innovation of public health law education can cultivate High-level talents of public health law education, which plays a vital role in solving the shortage of talents in the public health field of relevant institutions in free trade port

\section{The Necessity of Innovation in Public Health Law Education under the Background of Free Trade Port}

\subsection{Inherent Requirements for Promoting the Comprehensive Development of Higher Education in Hainan Free Trade Port}

Education is an important cornerstone of national rejuvenation and social progress. China's health law education is currently in an unbalanced development stage. According to the results of field research, in many universities in Hainan, only the Law School of Hainan University and the Department of Humanities and Social Sciences of Hainan Medical University offer health law-related courses, but these courses are all general courses. Students cannot deeply understand the hot, key and challenging issues in the field of the public health law. Thus, the higher education of health law in Hainan province has not started. According to "Overall Scheme of Hainan Free Trade Port Construction", the three stages of Hainan Free Trade Port construction will closely focus on the modern service industry dominated by education and medical care. Under this background, Public Health Law education will become an important part of the higher education system of the free trade Port. Innovative Public Health Law education can not only make up for the deficiencies of the development of higher education under the construction of the free trade Port, promote the further integration and development of higher disciplines such as medicine, law, pedagogy, etc., But also 
Volume 3 (2021)

transport a large number of interdisciplinary talents of medicine and law for the construction of the free trade Port. [1]

\subsection{Necessary Premise of Cultivating High-level Talents in Hainan Free Trade Port}

Talents are strategic resources to realize national rejuvenation and win an international competition. [2] As an interdisciplinary subject of medicine and law, traditional public health law education has a wide range of research and is challenging to study. It takes a lot of time to cultivate qualified personnel in the field of public health law. Therefore, due to the disciplined nature of public health law and the weak discipline foundation of public health law in Hainan, there is a severe shortage of talents in the field of public health law in Hainan. Innovative public health law education can input more Highlevel talents of public health law for the construction of Hainan Free Trade Port and improve the overall construction level of Hainan Free Trade Port. On the other hand, the innovation of Public Health Law education can promote the effective combination of medical resources and legal resources in the province, establish a long-term cooperation mechanism, realize the sharing of medical and legal education resources and scientific research to cultivate a group of compound excellent health Law talents who "understand both law and medicine, "have good theoretical literacy and solid practical ability.[3]

\subsection{Practical Needs to Promote the Healthy and Stable Development of Public Health Industry in Free Trade Ports}

At the twelfth meeting of the Central Committee for Comprehensive Deepening Reform, General Secretary Xi Jinping pointed out that combating the epidemic of new coronavirus pneumonia is a significant test for the national governance system and governance capacity-building. It is necessary to study and strengthen epidemic prevention and control, innovate and improve major epidemic prevention and control initiatives from the institutional mechanism, improve the national public health emergency management system, and improve the ability to respond to major public health emergencies.[4] Through the prevention and control of the 'Covid-19' epidemic, it can be seen that China' s public health laws and regulations are not perfect, there are loopholes in the judgment, evaluation, decision-making and prevention and control coordination mechanism of major public health risks, and there is a lack of public health law professionals.

Under the dual background of epidemic prevention and control of 'Covid-19' and the construction of free trade port, all aspects of food safety, medical and health, emergency treatment of sudden public health events are worthy of attention. In the process of Free Trade Port construction, international economic and trade cooperation will be more frequent. More foreign enterprises will be settled in Hainan, Hainan will also become more international events and large international expo site. At the same time, Hainan will face more challenges in the field of public health. Perfecting laws and regulations in public health in Hainan Province will become the top priority to ensure the safe development of free trade ports, which requires further clarification of the management responsibilities and authority of various departments in the public health system. To realize the orderly and scientific management of public health. Public health is closely related to social welfare, public health management and scientific research. Innovation of public health law education can cultivate High-level talents to promote public health legislation. In the future, when solving problems such as medical accidents, health and epidemic prevention, and sudden public health events, they can also achieve legal and orderly prevention and control. 


\section{Obstacles to Innovative Public Health Law Education in the Context of Free Trade Ports}

\subsection{Low Attention Paid to Public Health Law}

$\mathrm{Xxx}$ is a compulsory course for law and medicine majors. Health law courses are usually just general courses, and the marginalization of health law is obvious. In medical colleges, medical and health disciplines are the focus. In political and legal colleges, the focus of teaching is the secondary discipline of law. (Secondary subjects: The subject catalogue of our country is divided into subject categories, primary subjects (called 'professional category' in undergraduate education), secondary subjects (called 'professional category' in undergraduate professional catalogue) and tertiary subjects.) There is nothing related to 'health law 'or' medical law' in the secondary discipline catalogue of 'law' from the current national subject catalogue. Although some political and legal universities set up health law-related disciplines, most of them are to comply with the requirements of higher education management departments. Therefore, many aspects such as teacher allocation, curriculum setting and teaching methods solve no problems but for showing, and the function of training professionals is not really played. Some medical colleges and universities carry out public health law courses because the Ministry of Health of the People's Republic of China stipulates that the medical qualification examination must examine the knowledge of health law. (See the notice of the Ministry of Health on the issuance of " "Provisional Regulations of the Ministry of Health on the Qualification of Medical Qualification Examination' ".) However, most medical students still focus on health care-related disciplines. Because the health law in civil law can solve the general medical-legal problems, the course of health law has not attracted students' attention. However, in the context of the construction of the Free Trade Port in Hainan, the medical cause is becoming more and more international, the medical problems are more complex, and people's demand for health care is becoming more and more diversified. The level of health law education will directly affect the development level of medical causes in free trade port. (See Hainan Provincial Health Committee "Construction of Health System Adapted to Free Trade Port" at three sessions of the Sixth People 's Congress).

\subsection{The Rigid Teaching Model of Public Health Law}

Public health law involves a wide range of contents and covers a huge number of laws. However, due to the school system's construction, most colleges and universities adopt the cramming method of teaching. The teaching content only involves a small part of the health law content, and the teaching method is the collation and interpretation of health laws and regulations. The teaching model is superficial and generalized.[6] As an interdisciplinary subject of natural science and social science, the health law has the characteristics of compound content and strong practicality. Students of different majors have different requirements for the integration of practice and teaching. If one-sizefits-all mode is adopted, whether in law, medicine or other majors, students are educated in one way, resulting in unsatisfactory results. Nowadays, most of the classroom teaching of health law cases still stays at the level of 'case' or 'example', or teaches according to the idea of case answer, and the actual effect is not optimistic. [7] Law and medicine are both practice-oriented disciplines. Teachers 'cramming teaching methods can only build a basic knowledge framework for students but cannot improve students' subject literacy.

\subsection{The International Perspective of Public Health Law Needs to be Strengthened}

The construction of the Hainan Free Trade Port is an important measure for China to comprehensively improve opening up, build a new system of the open economy at a higher level, and form new advantages of international cooperation and competition. Therefore, the innovation of public health law education in the Free Trade Port must have a global perspective. At present, the universities offering public health law education in Hainan Province have not carried out exchanges and cooperation with overseas public health law universities, and the trend of international joint education is low. The teaching method of 'making cars behind closed doors' can no longer meet the 
practical needs of the construction of the international Free Trade Port in Hainan. The degree of internationalization of public health law teachers in Hainan Province is low. Most of the teachers who teach public health law are graduated from domestic universities. The number of teachers with overseas study experience in public health law is small, and there are few opportunities for universities to send teachers to visit and exchange abroad for the public health law. There is a certain gap between Hainan's public health law and foreign law education which takes the case from law clinic as the main teaching methods. Public health law education is still mainly taught in Chinese. The level of bilingual teaching needs to be strengthened, which is not conducive to the new situation of the internationalization of public health law education under the background of a free trade port. In addition, the curriculum of public health law is only aimed at the prominent problems of domestic public health law, which rarely reflects the frontier theories and hot issues of international public health law, and the research on public health law in various countries is very lacking.

\subsection{The Difficulty in Teaching Public Health Law}

Public health law includes the basis of health law, the legal system of emergency response to public health emergencies, the legal system of public health supervision, the legal system of drug management, the legal system of hospital management, and the legal system of medical accident treatment. (See "Health Law of the People 's Republic of China") These courses have many theories and laws, but there are few practical cases related to health law. Therefore, the textbooks are not vivid, resulting in students' lack of practical experience and interest in theory, which increases the difficulty of teaching. At present, the textbook of health law is old. Although there are thirty or forty kinds of teaching materials of health law, due to the large number of policies and regulations in the field of medical and health, the update speed is frequent, and the update of teaching content is often unable to keep up with the speed of policy system update.

Health law is an interdisciplinary subject with a wide range of contents. Public health law requires teachers to have the solid medical and legal knowledge, and medicine and law are two professional and difficult subjects. Moreover, only colleges and universities that simultaneously set up medicine and law can be able to train professionals in health law. However, colleges and universities that can set up health laws are faced with the problem of "school system construction" [8], so it is difficult to cultivate professionals who can teach health law under the traditional system. Suppose teachers of legal origin teach health law, due to the lack of medical knowledge. In that case, they may still follow the training mode of traditional legal talents to train health law talents, which will lead to the gradual disappearance of the difference between traditional legal disciplines and health law. Suppose the health law discipline is taught by teachers of medical background. In that case, it is difficult to achieve the integration of law and medicine in a short time because of their lack of legal education and legal literacy.

\section{Innovation Scheme of Public Health Law Education under the Background of Free Trade Port}

\subsection{Scientific Construction of Discipline Orientation to Improve the Attention of Health Law}

Under the difficult situation of epidemic prevention and control in 2020 and the unclear international anti-epidemic situation, the construction of the Hainan Free Trade Port will face great challenges. Under the premise that the epidemic will affect economic development in the next few years, the demand for talents in the field of health prevention and control in Hainan will be huge.( See Zhao Jinping, Chief Economist of National Research Think Tank, Honorary President of Hainan Open Economic Research Institute and former Minister of Foreign Affairs of Development Research Center of State Council : "New thoughts on the construction of Hainan Free Trade Port under the background of epidemic prevention and control" ") Therefore, it is necessary for colleges and universities in Hainan, such as law schools and medical schools, to establish relevant specialities and 
recruit students to cultivate specialized talents for health legislation, prevention and control and related economic development in Hainan.

The introduction of high-quality personnel in health law teaching, the compilation of high-quality textbooks and other learning materials, the provision of good health law teaching equipment and environment, and the improvement of the importance of major colleges and students to the health law major are the urgent problems faced by major colleges and universities to establish public health law major.[9] At the same time, the government departments should provide corresponding employment positions, set up specialized agencies responsible for public health affairs in Hainan Free Trade Port, and provide opportunities to establish health law majors in major colleges and universities. Hainan provincial government should also set up special financial funds, encourage students to study and apply for related majors, and support universities to open related disciplines. In addition, the health law courses related to law, medicine, and health science in universities in Hainan Province should be appropriately increased in-class hours to understand more knowledge of health law and receive more comprehensive health law education. At the same time, the assessment standard of health law courses should be improved accordingly so as to improve student's attention to the study of the health law.

\subsection{Adopting Immersion Teaching Method of Public Health Law}

In the past, teaching practice of law, mock courts, legal clinics, case scenario teaching and so on are all successful immersion teaching methods. These methods can enable students to give full play to their subjective initiative, use what they have learned, and maximize their practical ability to accumulate practical experience and improve their ability to deal with practical problems to better understand the corresponding theoretical knowledge. [10] Innovating Public Health Law education needs to introduce these methods into the teaching of Health Law, which is not only conducive to cultivating students "interest in learning Health Law but also allows more students to participate in it and to understand the social necessity, operation mechanism and basic principles of public health Law in real cases, instead of just knowing it but not knowing why it is. Hainan can cultivate more practical talents in the field of public health law through this immersive teaching method of public health law and inject more professional strength into the construction and development of Hainan Free Trade Port in the future. More academic exchanges should be carried out in medicine, health science, and law in the teaching process. Whether in legal clinics, mock courts or case plot discussions, students of related majors can be concentrated to learn and promote inter-disciplinary exchanges and cooperation. These tools help encourage students' learning and understanding of the subject of health law, thereby improving the effectiveness of public health law teaching.

\subsection{Expanding the Perspective of Internationalization of Public Health Law}

The construction of the Hainan Free Trade Port needs a large number of bilingual and international talents, which is based on the strategic positioning of 'exploring the establishment of a new open economy system and making Hainan an important open the door to the Pacific and the Indian Ocean' (The "guiding opinions on supporting Hainan to deepen reform and opening up in an all-round way" issued and implemented by the CPC Central Committee and the State Council on April 11,2018 pointed out that "adapt to the new situation of economic globalization, implement a more proactive opening strategy, explore the establishment of a new system of open economy, and build Hainan into an important opening door for China to the Pacific and Indian Oceans."). Under this condition, the health law talents trained by Hainan colleges and universities must serve the construction requirements of Hainan Free Trade Port and the requirements for applying public health law in the open economic system to be built in the future. Therefore, bilingual teaching of health law is fundamental in Hainan, which is the basis of training international talents of the health law. The bilingual teaching materials of health law should be compiled and published as soon as possible, the bilingual courses of health law should be formulated and introduced, the bilingual teachers of health law should be introduced from other provinces and even the whole world, and the corresponding international education experimental classes of health law should be established, so that students can 
adapt to the bilingual learning and application of health law as soon as possible, and create a good environmental foundation for the international application of health law in Hainan.

Based on a good language environment, the content of teaching should be in line with international standards, and teaching materials and education should involve more frontier knowledge and hot issues in the field of global public health. More international exchanges and cooperation should also be carried out. Students should be regularly sent to domestic and overseas experienced universities or international health organizations for study or internship. Experts and scholars in the field of international health law should be invited to visit Hainan to integrate teaching content with international standards and cultivate students' global vision. In the international education of law on this point to the law school of foreign economic and trade university do more successful, can draw the corresponding experience. [5]

\subsection{Reducing the Difficulty of Teaching Public Health Law}

Because of the difficulty of health law teaching, Hainan should optimize the teaching environment of public health law from reality. Although there is no mature health law teaching and curriculum system in Hainan Province, the teaching system of law and medicine in colleges and universities in Hainan Province has been relatively perfect, and the teachers are fairly complete. On the issue of improving the quality and specialization of teachers, we can give priority to training teachers with a medical and legal teaching background, let some teachers "go back to further education", carry out legal literacy training for teachers with a medical teaching background, and carry out medical literacy training for teachers with a legal teaching background, to cultivate local health law teaching talents in Hainan Province. On this basis, to further strengthen the teaching staff of health law and improve the teaching staff, we should also introduce talents of health law teaching from outside the province and even overseas to quickly and firmly construct the education cornerstone of health law speciality in Hainan Province in a short period. In the textbook and the related teaching material quality is not high ( mainly manifests in the case few, is far away from the reality and so on ) the question, Hainan Province should also begin to compile has the Hainan characteristic health law teaching material. On this issue, colleges and universities should actively cooperate with legal institutions, courts, hospitals and other practical departments and incorporate more social current affairs hot spots in textbooks and the latest health law cases with Hainan characteristics. In addition, to make up for the limitations of textbook compilation in case updating, the teaching of health law should actively encourage teachers and students to go out of school and move to practical departments, and take the latest cases as samples to understand the relevant theories and knowledge of health law more profoundly.

\section{References}

[1] See Xi Jinping: adhere to the road of socialist education development with Chinese characteristics and nurturing a new generation of capable young people who have a good and all-round moral, intellectual, physical, and aesthetical grounding in addition to a hardworking spirit, and who are well-prepared to join the socialist cause. Http://edu.feedle.com.cn/GB/8216/421254/index, last accessed August 20,2020.

[2] See Xi Jinping: secure a decisive victory in building a moderately prosperous society in all respects, strive for the great success of socialism with Chinese characteristics for a new era. http:// www. 12371. cn/ special/19da/bg/, Last visit: 20 August 2020.

[3] Guo Weilu, A Study on the Approaches of Public Health Law Education. [J] Law Science, 2020(04).

[4] See "News: Xi Jinping presided over the twelfth meeting of the Central Comprehensive Reform Commission, emphasizing the improvement of major epidemic prevention and control system and mechanism and the improvement of national public health emergency management system." http:// www. gov.cn/xinwen/ 2020-02 / 14 / content 5478865.htm Last visit date: August 20, 2020.

[5] See "National Strategic Feelings of Foreign Law Education - - Interview with Mei Xiaying, Dean of Law School of Foreign Economic and Trade University" published on December 12, 2019, 005th edition.

[6] MA Jingyao. Research on the Typification of Health Law Courses in Medical Colleges and Universities in China. [J] The Theory and Practice of Innovation and Entrepreneurship, 2020(3). 
Volume 3 (2021)

[7] Liu Liang. Specialized Teaching of Science of Health Law Desiderates Five Tremendous Changes. [J] Northwest Medical Education, 2011(10).

[8] He Jun, Ran Wei. Dilemma and path selection of legal education from the perspective of Health Law. [J] China Health Law, 2008(9).

[9] Dai Yanling. Reflections on the teaching reform of Health Law in medical colleges and universities. Journal of Guangxi College of Education, 2007(1).

[10] Liu Dahua. Practical exploration of participatory teaching in the teaching reform of Health Law. [A] Higher education, 2016 (6). 